December 2014

\title{
Digital vs. Print: Reading Comprehension and the Future of the Book
}

M. Julee Tanner

San Jose State University, juleetanner@gmail.com

Follow this and additional works at: https://scholarworks.sjsu.edu/ischoolsrj

Part of the Collection Development and Management Commons

\section{Recommended Citation}

Tanner, M. J. (2014). Digital vs. Print: Reading Comprehension and the Future of the Book. School of Information Student Research Journal, 4(2). https://doi.org/10.31979/2575-2499.040206 Retrieved from https://scholarworks.sjsu.edu/ischoolsrj/vol4/iss2/6

This article is brought to you by the open access Journals at SJSU ScholarWorks. It has been accepted for inclusion in School of Information Student Research Journal by an authorized administrator of SJSU ScholarWorks. For more information, please contact scholarworks@sjsu.edu. 


\title{
Digital vs. Print: Reading Comprehension and the Future of the Book
}

\begin{abstract}
The future of books and libraries is put into question by the increasing popularity of e-books and the use of computers as text platforms. In an effort to anticipate which reading platform-print, e-readers, or computers displays-will dominate in the coming years, recent research and experimental data on the suitability of each reading platform for reading comprehension will be considered, from the perspectives of optical issues, cognition, and metacognition. It will be shown that, while printed books are most conducive to learning from longer, more difficult texts, e-readers and computer displays offer convenience and some distinct advantages to readers in particular situations. This synthesis of current research will be helpful to librarians working in digital and print book purchasing and collection development, as well as those making long-range planning decisions.
\end{abstract}

\section{Keywords}

books, digital books, e-paper, reading comprehension, cognition, metacognition, libraries, collection development

\section{About Author}

M. Julee Tanner is currently pursuing a master's degree in library and information science at San Jose State University. She holds a master's degree in art history from the University of Chicago and a bachelor's degree in art history from Grinnell College. 
Recent sales data indicate that the meteoric rise of the digital book, and a consequent fall in purchases of traditional books, may have subsided. It seems likely that, at least in the short term, digital book sales will settle somewhere between $10 \%$ and $20 \%$ of the total market (Milliot, 2014). Cultural forecasters are again considering the possibility that print books will survive into the future, along with libraries as the ubiquitous brick-and-mortar institutions that lend books, in addition providing all the technology-based services that have come to define them in recent years. In an effort to determine what books and libraries might look like in the future, this article compiles current research on how reading comprehension is impacted by each of the three current reading platforms: print books, e-books, and books downloaded onto smartphones or computers. Although future advances in digital technologies will continue to enhance the convenience and ease with which e-books and computer texts are read, comprehension still seems to be the best indicator of the relative presence of each reading platform in years to come. If, because of superior optics, cognitive availability, or metacognitive suitability, one platform seems superior to the others, it may be assumed that it would dominate the book market in the future. If, as seems more likely, each platform is best suited for the comprehension requirements of different readers in different situations, the question of the future of books and libraries will remain complicated, yet still be more predictable. What seems definite at the outset is that, before making major investments in digital books and ereaders, librarians should be well aware of the strengths and limitations of the electronic platforms for the reading brain, regardless of short-term trends in the retail book market.

\section{Libraries and the Evolution of Book Lending}

In recent years, improvements in e-reader technology and the convenience of smartphone reading have made digital books a mainstream phenomenon. According to the Pew Research Center, 28\% of Americans read at least one e-book in 2013, up from 23\% in 2012 and 16\% in 2011 (Desilver, 2014; Rainie and Duggan, 2012). Yet this rise in demand for digital books has been largely unmet by libraries, who have had only limited success negotiating e-book purchases with publishing houses. Not until the summer of 2013 did all five of the major United States publishers agree to release at least some of their digital editions to libraries, and then at prices several times higher than the equivalent print editions. Currently, libraries most often purchase e-books under licenses that expire after a certain amount of time or a certain number of loans, limit or prohibit downloading and printing, or prevent a title from being loaned to different users simultaneously (Besen and Kirby, 2014). In part as a result of such restrictive licenses, only about $5 \%$ of books borrowed from public libraries are digital, according to the most recent data available (Rainie and Duggan, 2012).

Publishers' reluctance to make e-books available to libraries is understandable; it has long been assumed that readers who could access electronic editions through libraries would have little reason to purchase their own electronic or print editions. Yet as publishers' recent sales data has demonstrated, the distribution of e-books through libraries can actually enhance retail sales, especially for books by newer authors who might be "discovered" through free downloads at the library. For this reason, it is 
expected that publishers may begin to offer lending institutions greater access to digital books, at prices more comparable to print editions (Enis, 2014).

The improving economics of e-book lending of course presents libraries with an opportunity to keep pace with an increasingly technology-driven culture, to provide patrons all-hours access to even more reading materials through their online accounts. Yet as publicly funded institutions bound to promote literacy and learning, libraries have goals beyond more convenient book borrowing, and are guided by a mission more nuanced than simply staying relevant in the information age. The decision to purchase a digital or print edition should be made with an understanding of the suitability of each platform for the comprehension needs of the likely reader, and whether a particular book will be read for entertainment or edification. To facilitate such decision-making, this paper compiles current research on the advantages of reading from printed books, ereaders, and computer displays from the perspectives of the optical issues, cognitive needs, and metacognitive habits of different readers. More than cost and convenience, these are the factors that should be considered when deciding between digital and print formats.

\section{Optical Issues: LCDs, E-Paper, and Print}

The visual focus required when reading, whether it is done on paper, a reader, or a computer screen, necessitates a reduction in the frequency of eye blinks. Reduced blinking causes an increase in the rate of evaporation of tears on the eyes, a condition commonly referred to as "dry eye," and the possibility of attendant fatigue, headache, blurred vision, and light sensitivity. It has been experimentally demonstrated that ocular discomfort and perceptual difficulty, regardless of the reading platform, can compromise one's ability to learn from a text, a phenomenon that becomes more pronounced as the duration of a reading session is lengthened and the difficulty of the text is increased (Conlon \& Sanders, 2011). When the optical ill effects of reading on paper and computer screens are compared, the digital text consistently rates far worse, though the transition from cathode ray tube (CRT) terminals to liquid crystal displays (LCDs) has somewhat improved the optics of computer reading (Cf. Wästlund et al., 2005 and Benedetto et al., 2013).

While it is possible that future improvements in screen technology could bring the incidents of dry eye when reading on a computer closer to those of reading on paper, a recent investigation by optometrist Mark Rosenfield (2011) demonstrates that this is unlikely, for dry eye is caused not only by the illuminated display, but also by the angle at which computer text is normally read. Rosenfield explains that the more upright angle of a computer screen results in greater exposure of the cornea and only partial eye blinks. With printed books, however, which are read at a lower angle, a more closed eye position and complete eye blinks are maintained (Rosenfield, 2011). Given that the main advantage to reading on a computer is the ability to multitask with a keyboard, the upright angle of the screen seems inherent to the platform. To the extent that the visual discomfort caused by dry eye impacts reading comprehension, printed books will continue to be superior to computer screens, especially when one is trying to read longer, more challenging texts. 
From the standpoint of visual perception, e-books present a greater challenge to the dominance of print. The latest generation of e-readers uses an e-paper technology (also known as "e-ink," from the proprietary brand E Ink) that mimics the appearance of print on paper; instead of the backlit display of LCDs, e-paper displays reflect light just as does the printed page of a book. In an experiment comparing the impact on visual perception of reading for more than an hour from printed paper, e-paper, and an LCD reader, cognitive ergonomics researcher Simone Benedetto (2013) confirmed that e-paper is the optical equivalent of print on paper. Test subjects blinked at the same rate while reading from e-paper and print (.6 blinks per second), and blinked considerably less often when reading from the LCD (about .4 blinks per second). Benedetto also measured changes in visual alertness by administering a critical flicker fusion (CFF) test before and after subjects' reading sessions. The results indicated a decrease in visual alertness that was equivalent for e-paper and printed paper, and a significantly greater drop in visual alertness for the LCD (Benedetto, 2013; the CFF test administered by Rosenfield showed an even more pronounced decrease in alertness for readers of LCDs [Rosenfield, 2011]). Not surprisingly, test subjects also reported symptoms of dry-eye induced visual fatigue after reading from the LCD for an hour, but reported no such symptoms after reading from the e-paper and print platforms (Benedetto, 2013, p. 5). Benedetto's experiment confirms manufacturers' claims of e-paper equivalence to printed paper.

Another researcher, optometrist Paul Harris, has conducted similar investigations and now believes that e-paper is potentially superior to printed paper in terms of optics, due to the customizable nature of the platform. Harris has demonstrated that subjects actually show improved reading comprehension when point size and line spacing are increased (cited in Withers, 2013). Researcher in applied psychology Elizabeth Conlon has also attributed readers' visual discomfort to the repetitive striped pattern of small, single-spaced lines of text, providing further evidence that the potentially superior optics of e-readers might actually enhance comprehension (Conlon \& Sanders, 2011).

Optical evidence for the superior readability of e-books and printed books over computer screens is not, however, unchallenged. A study led by linguist Franziska Kretzschmar (2013) compared the experiences of younger and older readers across all three platforms. The results of these experiments at first seem to oppose previous research. Using electroencephalogram (EEG) and eye tracking data to measure test subjects' cognitive effort while reading, in addition to administering reading comprehension tests, Kretzschmar found that older adults actually read with the greatest ease and understanding from LCDs, probably because of that platform's high contrast backlit display. Among younger adults, no significant difference in cognitive effort or comprehension was found when reading from print, e-paper, and LCDs. While Kretzschmar's study could be dismissed as an inevitable experimental outlier, a closer look at her procedure reveals that her conclusions are actually not incompatible with those of other researchers. For example, the texts used in Kretzschmar's experiments were comparatively short, averaging 222 words, and comprehension questions were trueor-false (Kretzschmar et al., p. 3). Benedetto's texts, by contrast, averaged over 16,000 words, requiring more than an hour of sustained reading to complete, and his comprehension questions were multiple choice (Benedetto, 2013, p. 3). Kretzschmar also presented her texts in a larger point size with thirteen lines of text on each page, compared to eighteen lines of text per page in Benedetto's procedure. Shorter texts, a 
lower standard for comprehension, and improved optical conditions together made Kretzschmar come to a conclusion different from that of other researchers.

When considered alongside the findings of Rosenfield (2011), Benedetto (2013), Harris (2013), and Conlon (2011), Kretzschmar's research further refines our understanding of the unique functionalities of print, e-paper, and LCDs: For shorter reading sessions that require less cognitive effort, the optical qualities of an LCD computer screen are sufficient, which may explain why many people have abandoned print newspapers and magazines in favor of the greater convenience of on-line editions. However, the non-illuminated displays of e-paper and print books are better suited to reading longer, more challenging texts. All readers might reduce eyestrain by increasing point size and line spacing on e-readers. Finally, older adults will likely be able to follow the high-contrast text of LCDs with greater ease and enhanced comprehension.

\section{Cognition: Digital vs. Print}

Although researchers studying the effectiveness of different reading platforms are primarily concerned with objective measures of optical challenge and reading comprehension, both Benedetto (2013) and Kretzschmar (2013) do also consider participants' subjective preferences, and here the results are consistent. Both studies show an overwhelming preference for print books over both digital media platforms. Even older adults, who in Kretzschmar's experiment read from LCDs with the greatest ease and comprehension, identified print books as the most "pleasant" to read, by a factor of nearly three to one (Kretzschmar et al., fig. 2). Likewise, the current generation of young people, the digital natives who should have no cultural bias for the printed word, report in survey after survey that they prefer learning from books to learning from screens; many report that if they do discover an important text on the internet they are likely to print it out before attempting in-depth reading (Jabr, 2013, "Navigating," para. 10). It must be concluded that the general preference for print- over screen-reading goes beyond optical issues and force of habit to cognition, or the way texts are processed and stored in our minds.

Essential to understanding how uniquely well-suited printed texts are for the reading brain is the fact that there are no genetic or biological structures dedicated solely to reading. Instead, we read by connecting neural structures originally developed for vision, object recognition, and spoken language to the processes of letter and word recognition and the short-term memory storage necessary for sustained thought. The same cognitive structures that evolved for navigation and communication in the physical world have been adapted to accomplish the learned behavior of reading (Wolf, 2007). To the reading brain, therefore, letters and words exist as physical objects, and the text they compose forms a kind of thought-landscape where meaning associated with words occupies a specific location. This is why, when people are trying to locate a particular piece of information they have read, they often can remember where in a printed book they came across it-high or low on a page, verso or recto, and at a certain depth in the page stack. Paging back through a text to find a particular passage remembered by its location is the cognitive equivalent of retracing one's steps through a forest, searching for familiar landmarks along the way (Jabr, 2013, "Navigating," para. 3; Mangen, 2012, p. 
65). Obviously, when trying to study from a virtual text, the reader is deprived of this ability to associate thoughts with real-world locations.

To provide experimental support for the idea that the physicality of a text is important for comprehension, psychologist Anne Mangen (2013) devised a reading test that would require subjects to return to a previously read, four-page text to answer comprehension questions. Half of the subjects read from an unpaginated pdf file, while the other half read from printed paper. The subjects using the paper condition did perform significantly better on the comprehension test. Based on this result and other researchers' findings, Mangen sees a relationship between reading comprehension and one's ability to mentally reconstruct a text: ". . . the fixity of text printed on paper supports a reader's construction of the spatial representation of the text by providing unequivocal and fixed spatial cues for text memory and recall" (Mangen, 2013, p. 66). Mangen did not include an e-reader in her study. While it does seem that the page-at-a-time presentation of an ereader, coupled with the action of tapping to turn pages, would provide the reader with some ability to locate ideas in two dimensions, the sense of the number of pages turned and the thickness of the book would remain abstract. Whether it is read on an LCD or an e-reader, it does seem that the very intangibility of screen text inhibits the cognitive process.

Mangen's study (2013) demonstrated the difficulty that readers of an unpaginated pdf file encountered when trying to relocate information previously read. Some might counter, however, that the static pdf file used in her experiment was not taking advantage of a unique capability of virtual text: hyperlinks. By enabling a reader to selectively click on terms that require further clarification, or on digressions of special interest, it was once thought that a reader of hyperlinked text would be empowered to take control of his or her own edification, to read quickly past familiar information and focus on what is new. Contrary to this hope, countless studies from the 1990s to the present have shown that readers of linear text actually understand better, learn more, and remember more of what they have read than readers of hyperlinked text. A consistent explanation for the failure of hyperlinked text as a learning tool is that simply deciding whether or not to click on a link increases a reader's cognitive load. Each time a link is encountered, it has to be momentarily evaluated. To the reading brain, each link represents a problem-solving task that is extraneous to the actual content of a text. If a link is followed, the reader's focus is changed in a way that might be difficult to connect with previously encountered ideas (Carr, 2011, pp. $126-28$ ). To return to the analogy of the text as a forest of ideas along a path, science writer Ferris Jabr likens clicking on hyperlinks to repeatedly "teleporting" off the path: "Instead of hiking the trail yourself, the trees, rocks, and moss move past you in flashes with no trace of what came before and no way to see what lies ahead" (Jabr, 2013, "Navigating," para. 5).

Even if a reader consciously decides not to follow links, the distraction of seeing colored, clickable text is enough to inhibit comprehension. According to neuroscientist Joel Pynte, who has investigated the effects of typographical errors on eye movements, any unfamiliar text in the parafoveal region will draw the eye and interrupt the momentto-moment processing of information during saccades, thereby compromising speed and concentration (Pynte, 2004, p. 201. See also Zhang, 2012, p. 6, for a discussion of how interrupting saccadic eye movements can prevent a reader from choosing the next most salient lexical fixation point). 
The cognitive distraction posed by clickable text can no doubt be confirmed by anyone who has spent time digressing through a string of Wikipedia articles. Slightly more controversial, however, is the idea that, when reading for understanding as opposed to entertainment, the screen itself might interfere with comprehension. In a 2005 study by psychologists Jan Noyes and Kate Garland, it was found that, while test subjects who read a digital (CRT) introductory economics text were able to perform as well on a comprehension test as subjects who read the same text in print form, their methods of cognitive processing did differ. In essence, the readers of the printed text understood the material, while the readers of the digital text only remembered the material. The cognitive difference between understanding and remembering is significant, as once a concept is understood it becomes a long-term memory no longer tied to its original source-it is known. Without understanding, a newly learned concept is nothing more than a short-term memory that may not be available as a foundation for more difficult concepts to be taught later on (Noyes and Garland, 2005, as cited in Jabr, 2013, "Exhaustive," para. 2).

Noyes and Garland's experiment (2005) might account for the experience of longtime astronomy professor David Bruning, who believes that today's digital native students no longer have the patience necessary to truly engage with and understand difficult reading material:

. . . my students appear to be passive recipients of the written word; they memorize sentences as if they were oracle bones. They do not participate in the give-and-take between author and reader that I have come to expect. Instead of wishing to be challenged by ideas strewn through the pages, they wish to be assured that the manipulation of the electronic file is tantamount to education. (Bruning, 2012, p. 11)

The superficial approach to reading exhibited by Professor Bruning's students may be a consequence of the computer platform itself. Given that students use their computers for recreational reading, e-mailing, social networking, Skyping, shopping, sharing music, and gaming, it seems unlikely that they would easily sit before these devices receptive to concentrated study. It requires patience to learn from a text, patience to follow an author's logic through unfamiliar territory, and patience to constantly review new concepts to confirm one's understanding. A computer might not be conducive to such effortful deliberation. In the words of cognitive researcher Rakefet Ackerman, "The common perception of screen presentation as an information source intended for shallow messages may reduce the mobilization of cognitive resources that is needed for effective self regulation" (Ackerman and Goldsmith, 2011, "Metacognitive Learning," para. 7).

Noyes and Garland (2005), Ackerman and Goldsmith (2011), and Professor Bruning have all concluded that computer screens are not conducive to reading longer academic texts. It might be expected that the e-reader platform would perform better, combining as it does the convenience of a screen with the dedicated text presentation of a book. As previously mentioned, however, this was not the case in the two experiments that rated readers' subjective experiences of paper, e-paper, and LCD texts (Benedetto et al., 2013; and Kretzschmar et al., 2012).

The lack of enthusiasm on the part of many for e-books may be explained by what two researchers in information management are referring to as the "haptic dissonance" of 
e-readers. Jin Gerlach and Peter Buxmann define haptic dissonance as the "perceived unpleasantness" of an object that does not correspond to one's previous senseexperiences of the object (Gerlach and Buxmann, 2011, "Defining Haptic Dissonance," para. 2). In the case of e-books, this would translate to an expectation that a book should have bound, turnable, paper pages; a heft and thickness that reflects its length; a cover and binding with a non-technical feel that reflect its quality and durability; and a condition of use that reflects its age. Indeed, these were among the many physical qualities that a group of avid readers reportedly missed in their experience of the e-reader platform. Other comments made by the e-reader test group were that the e-reader felt "artificial," "disturbing," and "distant" (Gerlach and Buxmann, Tables 2, 3, and 6). Because the real-world qualities of a book were missing from the e-reader, $83 \%$ of the participants in the researchers' survey group strongly preferred paper books e-readers (Gerlach and Buxman, "Conceptualizing Haptic Dissonance," para. 5).

The sentiments of Gerlach and Buxman's test group are echoed by book critic David L. Ulin, who writes that, although he is an enthusiastic user of the latest digital technologies, when it comes to reading texts, he finds e-books "inhospitable":

I think in pages, not in screens; I like the idea of the book as object, of the book as artifact, of reading as a three-dimensional, tactile experience, in which the way a text looks or feels or even smells has an influence of how, or whether, I engage. (Ulin, 2010, p. 121)

Given the undeniable convenience of being able to carry a library of reading in a lightweight tablet, and the optical superiority of e-paper technology, the concept of haptic dissonance seems to be the best explanation for why retail e-book sales have not completely outpaced print book sales. In her research for Microsoft, Abigail Sellen has found that, when people discover an e-book they really enjoy, they tend to also buy the print version (Jabr, 2013, "Attitude Adjustments," para. 3). When it comes to readers' favorites, having access to virtual text does not, it turns out, bring the same pleasure as holding, reading, turning the pages of, and actually owning the printed book.

\section{Metacognition: Digital vs. Print}

Despite decades of work by computer and e-reader engineers and designers to improve the optics, display, and ease of navigation of virtual texts, readers still have a general preference for the print presentation, especially when it comes to longer, more challenging material. Some researchers are beginning to think that this long-standing preference for print might be more attitudinally based than objective, and reflect readers' inability to actively engage with digital texts from which they are trying to learn. Given the previously discussed importance of the physicality of a text for comprehension, and the fact that feeling "distant" from a text is a commonly heard criticism of e-books, this metacognitive approach to research does seem promising.

Rakefet Ackerman is a leading researcher in the metacognitive strategies people employ when reading, and his investigations do reveal significant differences between the print and digital platforms. In a 2010 experiment, Ackerman tested college students' ability to actively study and learn from five different challenging expository texts of about 1,200 words each, on both digital and paper platforms. Both groups of students 
were encouraged to underline, highlight, and take marginal notes, the digital group using familiar word processing tools, and the paper group writing with pencils and highlighters on the printed texts. When the students in the two test conditions were limited in the amount of time they could spend with their texts, on-screen performance was nearly identical to on-paper performance; comprehension questions were answered with about $62 \%$ accuracy. However, when the experiment was repeated with a new selection expository texts, and the students were allowed as much time as they thought necessary to interact with and come to an understanding of the material, the group using pens on paper earned test scores about 10 points higher than their virtual-learning counterparts. While the enhanced learning of the paper-and-pens condition may not in itself be surprising, a second finding does shed new light on the ability of readers of real-world texts to self-regulate their cognitive process: In both experiments, the on-paper learners were able to predict their performance on the comprehension test with reasonable accuracy (to within 4 percentage points on average), while the on-screen learners greatly overestimated how well they knew the material (by 10 percentage points on average; all statistics in Ackerman \& Goldsmith, 2011, fig. 2). Not only was it more difficult for the virtual learners to understand the material put before them, they also had a harder time judging their degree of understanding. On some level, however, it seems that studentreaders often do question their ability to learn from digital texts, and it is this "metametacognitive judgement" (Ackerman \& Goldsmith, 2011, "Metacognitive Learning Regulation," para. 6) that leads them to print out on-screen materials when deeper study and literal pen-to-paper interaction with readings are required (Ackerman \& Goldsmith, 2011, para. 2).

Two other investigations into the use and effectiveness of metacognitive strategies are worth considering, as they indicate that these study aids might not be necessary when a text, whether printed or virtual, is less challenging to the reader. In a 2003 experiment led by College Board researcher Jennifer Korbin, it was found that, when on-screen and on-paper GRE sample tests were administered to college students, the option to underline and take notes had no measurable effect on students' scores. It was observed that students using the paper condition did underline important information more frequently, possibly indicating a greater comfort with actual as opposed to virtual interaction with a text. It seems likely, however, that this metacognitive strategy was simply not necessary, given that the reading passage under consideration was grade level appropriate and only 55 lines long (Korbrin \& Young, 2003).

A second investigation, undertaken in 2013 by psychologist Sara J. Margolin, compared student comprehension test scores on 500-word narrative and expository texts that were read on paper, on e-paper readers, and on LCD computers. After comprehension tests were completed, subjects self-reported the metacognitive strategies that they had employed while reading. In terms of students' test scores, the most significant finding is that they performed the worst on the test for the expository passage read on the e-reader platform, by four points on a hundred-point scale. While this performance difference may be slight, it is significant because the greatest difference in metacognitive strategy was also found among the users of e-readers, in their reluctance to review previously read passages by virtually turning back pages. It seems that the perceived unwieldiness of screen-tapping to turn pages did negatively impact 
comprehension of expository texts on the e-reader platform (Margolin et al., 2013, Table 2).

Since monitoring one's understanding while reading, reviewing previously read material if necessary, underlining, and taking marginal notes are so vital to the comprehension of more challenging texts, it is important for students and educators to know how applicable these metacognitive strategies are to virtual texts. As the abovementioned studies indicate, learning on paper with pen in hand is more effective to the extent that a text presents a cognitive challenge because of its length or difficulty. Recent experiments by psychologists Pam A. Mueller and Daniel M. Oppenheimer (2014) confirm that taking notes in cursive facilitates comprehension better than typing notes on a keyboard, possibly because the greater speed of typing leads to verbatim notes, while note taking in cursive tends to be a synthesis of content in a reader's own words. The process of rephrasing information leads to better understanding and longer-term memory storage (Mueller \& Oppenheimer cited in Konnikova, 2014). According to cognitive neuroscientist Naomi Wolf, the physical act of writing facilitates abstract thinking and enables people to communicate ideas with greater precision (Wolf, 2007, pp. 65-66). Given the demonstrated physicality of reading, it seems likely that typing on a keyboard is, to the writing brain, the cognitive equivalent of reading virtual text, and therefore a more indirect and inferior way of achieving understanding.

\section{Conclusion}

As this article demonstrates, print books are still the best suited to the optical, cognitive, and metacognitive requirements of the reading brain. While e-paper technology has been shown to be the optical equivalent of print on paper, e-readers still are lacking in the physicality that has been shown to be so important for comprehension. E-readers also lack the haptic qualities that readers enjoy about books, and seem only willing to give up only when convenience and portability are at a premium. In terms of metacognition, ereaders provide limited opportunities for text interaction, while virtual page turning has been demonstrated to discourage review of previously read material. Computer-read texts have all the limitations of e-readers without the superior optics of e-paper, and the added cognitive disadvantage of distractions from multitasking. Hyperlinks, once thought to streamline the learning process, have instead proven to interrupt the seamlessness of the reading process from perception to thought processing, and this is when they are passed over. If links are actually followed, the lack of textual linearity is sure to lead to confusion. When learning from a text is the objective of reading, printed books will remain the preferred format.

Now that the major American publishing houses are beginning to see the value in making at least their newer titles available to libraries as e-books, price and availability should soon no longer be limiting factors for lending institutions wishing to expand their digital holdings. Yet libraries are not simply intermediaries between publishers and the reading public, and collection development is not simply a matter of economics. Librarians in charge of purchasing and long-range planning will best serve their patrons by basing their decisions on the findings of researchers studying the physiological and cognitive needs of readers, and their metacognitive habits. In terms of convenience, patrons would undoubtedly benefit from a library's partial conversion to virtual texts, and 
space made available by a reduction in physical books could be used for public access computers and community gathering spaces. But libraries that exist in the ether alone will not advance the educational needs of society. Given that the most recent research brings into question the efficacy of on-screen learning, librarians have a responsibility to ensure continued public access to the format best adapted to human cognition, the printed book. 


\section{References}

Ackerman, R. \& Goldsmith, M. (2011). Metacognitive regulation of text learning: On screen versus on paper. Journal of Experimental Psychology: Applied 17(1). doi:10.1037/a0022086

Benedetto, S., Drai-Zerbib, V., Pedrotti, M., Tissier, G., \& Baccino, T. (2013). E-readers and visual fatigue. PLOS ONE 8(12). doi:10.1371/journal.pone.0083676

Besen, S. M. and Kirby, S. N. (2014). Lbrary demand for e-books and e-book pricing: An economic analysis. Journal of Scholarly Publishing 45(2), 148 - 141. doi:10.3138/jsp.45.2.002

Bruning, D. (2012). What purpose reading? Mercury Magazine 41(4), 11.

Carr, N. (2011). The shallows: What the Internet is doing to our brains. New York: W. W. Norton.

Conlon, E. \& Sanders, M. (2011). The reading rate and comprehension of adults with impaired reading skills or visual discomfort. Journal of Research in Reading 34(2), 205-209. doi:10.1111/j.1467-9817.2009.01421.x

Desilver, D. (2014, January 21). Overall book readership stable, but e-books becoming more popular. Fact Tank. Retrieved from http://www.pewresearch.org/fact-tank/

Enis, M. (2014, August 5). With all "Big Five" ebooks now available, ebook vendors assess the road ahead. Library Journal. Retrieved from http://www.thedigitalshift .com

Gerlach, J. \& Buxman, P. (2011). Investigating the acceptance of electronic books-The impact of haptic dissonance on innovation adoption. ECIS 2011 Proceedings, Paper 141.

Jabr, F. (2013, April). The reading brain in the digital age: The science of paper versus screens. Scientific American. Retrieved from http://www.scientificamerican.com /article/reading-paper-screens/

Konnikova, M. (2014, June 2). What's lost as handwriting fades. The New York Times. Retrieved from http://www.nytimes.com/2014/06/03/science/whats-lost-ashandwriting-fades.html?module=Search\&mabReward=relbias\%3Ar\%2C\%7B\% $221 \% 22 \% 3 \mathrm{~A} \% 22 \mathrm{RI} \% 3 \mathrm{~A} 5 \% 22 \% 7 \mathrm{D}$

Korbin, J. \& Young, J. (2003). The cognitive equivalence of reading comprehension test items via computerized and paper-and-pencil administration. Applied Measurement in Education 16(2), 115 - 140. 
Kretzschmar, F., Pleimling, D., Hosemann, J., Füssel, S., Bornkessel-Schlesewsky, \& Schlesewsky, M. (2013). Subjective impressions do not mirror online reading effort: Concurrent EEG-eyetracking evidence from the reading of books and digital media. PLoS ONE8(2). doi:10.1371/journal.pone.0056178

Mangen, A., Walgermo, B. R., \& Brønnick, K. (2012). Reading linear texts on paper versus computer screen: Effects on reading comprehension. International Journal of Education Research 58, 61-68. doi:10.1016/ijer2012.12.002

Margolin, S. J., Driscoll, C., Toland, M. J., \& Kegler, J. L. (2013). E-readers, computer screens, or paper: Does reading comprehension change across media platforms? Wiley Online Library. doi:10.1002/acp.2930

Milliot, Jim (2014, April). Print, digital book sales settle down. Publishers Weekly. Retrieved from http://www.publishersweekly.com/pw/by-topic/industrynews/publisher-news/article/62031-print-digital-settle-down.html

Pynte, J., Kennedy, A. \& Ducrot, S. (2014). The influence of parafoveal typographical errors on eye movements in reading. European Journal of Cognitive Psychology $16(1 / 2), 178-203$.

Rainie, L. and Duggan, N. (2012). E-book reading jumps; print book reading declines. Pew Internet and American Life Project. Retrieved from http://libraries.pew internet.org/files/legacy-pdf/PIP_Reading\%20and\%20ebooks_12.27.pdf

Rosenfield, M. (2011). Computer vision syndrome: A review of ocular causes and potential treatments. Ophthalmic and Physiological Optics 31(5). doi:10.1111/j.1475-1313.2011.00834.x

Ulin, D. (2010). The lost art of reading: Why books matter in a distracted time. New York: Sasquatch Books.

Wastlund, E., Reinikka, H., Norlander, T., \& Archer, T. (2005). Effects of VDT and paper presentation on consumption and production of information: Psychological and physiological factors. Computers in Human Behavior 21(2). doi:

10.1016/j.chb.2004.02.007

Withers, N. (2013). Reading devices-Comprende? Can the device that you read from really change your reading speed and comprehension? Optometry Today 53(15).

Wolf, M. (2007). Proust and the squid: The story and science of the reading brain. New York: Harper Perennial.

Zhang, H., Yan, H-M., Kendrick, K. \& Li, C. (2012). Both lexical and Non-Lexical characters are processed during saccadic eye movements. PLoS ONE 7(9). doi:10.1371/journal.pone.0046 